\title{
Noncontingent and Response-Contingent Intravenous Ethanol Attenuates the Effect of Naltrexone on Hypothalamic-Pituitary-Adrenal Activity in Rhesus Monkeys
}

\author{
Keith L. Williams, Jillian H. Broadbear, and James H. Woods
}

\begin{abstract}
Background: The mechanism by which the opioid antagonist naltrexone suppresses overconsumption of ethanol is unclear. Oral ethanol consumption in humans increases hypothalamic-pituitary-adrenal (HPA) activity, and recent studies suggest that naltrexone may reduce ethanol consumption by modifying the HPA-stimulating effects of ethanol. The purpose of this study was to measure in rhesus monkeys the effects of ethanol and naltrexone, alone and in combination, on plasma levels of adrenocorticotropin hormone (ACTH).

Methods: Nine adult male and female rhesus monkeys with chronic, indwelling intravenous catheters were maintained on tethers that allowed ethanol delivery and blood sampling. In one study, the monkeys received intramuscular injections of saline or $0.32 \mathrm{mg} / \mathrm{kg}$ naltrexone followed by noncontingent intravenous bolus infusions of saline or 0.3 to $1.8 \mathrm{~g} / \mathrm{kg}$ ethanol. In a second study, other monkeys were given intramuscular injections of saline or 0.01 to $0.3 \mathrm{mg} / \mathrm{kg}$ naltrexone and subsequently responded on levers to receive intravenous saline or ethanol $0.03 \mathrm{~g} / \mathrm{kg}$ per injection.

Results: Ethanol, delivered either response contingently or noncontingently, did not produce systematic changes in ACTH plasma levels. Naltrexone alone produced increases in plasma ACTH that were attenuated by the subsequent administration of noncontingent or response-contingent ethanol. Naltrexone also produced dose-dependent reductions in intravenous ethanol self-administration. Linear regression analysis indicated that ethanol intake was negatively correlated with the plasma levels of ACTH over time.

Conclusions: The route of administration may modulate ethanol's effects on HPA activity. Ethanol may attenuate naltrexone's effect on the HPA axis by impairing HPA axis sensitivity to other stimuli. The negative correlation between ethanol intake and ACTH levels supports the notion that naltrexone's effect of increasing HPA axis activity may be related to its ability to suppress ethanol consumption.
\end{abstract}

Key Words: ACTH, Ethanol, Naltrexone, Self-Administration, Rhesus Monkeys.

A DMINISTRATION OF INTRAPERITONEAL injections of ethanol in rodents or oral ethanol in humans produces increases in plasma levels of adrenocorticotropin hormone (ACTH) and corticosterone or cortisol, presumably by activating the hypothalamic-pituitary-adrenal (HPA) axis (Inder et al., 1995; McCaul et al., 2001; Mendelson and Stein, 1966; Merry and Marks, 1969; Rivier, 1996). Naltrexone, which is effective in suppressing ethanol

From the Department of Psychology, Grand Valley State University, Allendale, Michigan (KLW); Department of Physiology, Monach University, Clayton, Australia (JHB); and Department of Pharmacology, University of Michigan, Ann Arbor, Michigan (JHW).

Received for publication July 31, 2003; accepted December 9, 2003.

Supported by the USPHS through NIAAA Grant AA-11424 and NIDA Grant DA-00254.

Reprint requests: Keith L. Williams, PhD, Department of Psychology, Grand Valley State University, 2224 Au Sable Hall, 1 Campus Dr., Allendale, MI 49401; Fax: 616-895-2480; E-mail: willikei@gvsu.edu.

Copyright (c) 2004 by the Research Society on Alcoholism.

DOI: 10.1097/01.ALC.0000121655.48922.C4 consumption in heavy drinkers and alcoholics, also increases plasma ACTH and cortisol levels in most studies in humans (e.g., Farren et al., 1999; Mendelson et al., 1986; Wand et al., 2001). Some investigators have suggested that the HPA response to ethanol may be the basis for the reinforcing effects of ethanol and also the basis for the ability of naltrexone to decrease ethanol consumption (McCaul et al., 2001). However, there is a lack of agreement on how naltrexone and ethanol interact on the HPA axis in human subjects. McCaul et al. (2001) found that naltrexone alone had no effect on ACTH or cortisol levels but that it decreased the HPA-stimulating effects of a large $(1.0 \mathrm{~g} / \mathrm{kg})$ dose of oral ethanol in heavy drinkers. These investigators suggested that "This [naltrexone-induced] dampening of hormonal responses may contribute to the therapeutic effectiveness of naltrexone for reducing alcohol liking. .." (p. 537). O'Malley et al. (2002), conversely, observed that plasma levels of ACTH and cortisol were increased in alcohol-dependent subjects who were drinking ethanol after chronic naltrexone administration, but not in subjects 
who were drinking ethanol in the absence of naltrexone. The higher levels of ACTH in the naltrexone-treated, ethanol-consuming subjects were associated with a decreased urge to drink and decreased ethanol consumption. The researchers hypothesized that "naltrexone may reduce drinking via suppressing craving for alcohol and that this effect may be related in part to naltrexone's ability to activate the hypothalamo-pituitary-adrenocortical axis" (p. 19). In both of these studies, naltrexone was given orally for 6 or 8 days before ethanol was consumed, but in the McCaul et al. study, three drinks were assigned to be drunk over a 15-min period. In the O'Malley et al. study, subjects could choose whether or not to drink four alcoholic drinks per hour for $2 \mathrm{hr}$ or to accept $\$ 3$ for each drink they did not consume. It is therefore possible that different HPA responses to ethanol in combination with naltrexone result when subjects have greater control over their ethanol intake.

Although HPA activity increases in response to intraperitoneal injections of ethanol in rodents and in response to oral ethanol consumption in humans, there is no evidence that ethanol increases HPA activity in rhesus monkeys. In this study, ACTH levels were measured over time after noncontingent or response-contingent intravenous ethanol administration in rhesus monkeys to determine whether ethanol increases stress hormone levels in monkeys, as it seems to do in rats and in most studies in humans. The effects of intramuscular naltrexone on ACTH levels were also measured over time. In addition, the ability of naltrexone to modify intravenous ethanol intake and the effect on ACTH levels of the combination of naltrexone and either response-contingent or noncontingent ethanol were determined.

\section{METHODS}

\section{Subjects}

Six adult male and three adult female rhesus monkeys (Macaca mulatta) weighing 6.4 to $13.7 \mathrm{~kg}$ were used. The monkeys received food and water ad libitum and were treated according to the Guide for the Care and Use of Laboratory Animals (National Research Council, 1996). All monkeys had intact adrenal glands and gonads.

\section{Apparatus}

The monkeys were housed individually in stainless-steel cages measuring $83.3 \times 76.2 \times 91.4 \mathrm{~cm}$ (Bryan Research Equipment Corp., Bryan, TX). The monkeys wore a Teflon mesh jacket (Lomir, Malone, NY) that was attached to the back of the cage via a flexible stainless-steel tether. After habituation to the cage and restraint device, the monkeys received an indwelling silastic catheter that was inserted into a femoral vein. Catheters were inserted during aseptic surgery with $10 \mathrm{mg} / \mathrm{kg}$ ketamine and $2 \mathrm{mg} / \mathrm{kg}$ xylazine anesthesia. After placement in the vein, the catheter was guided subcutaneously to the midscapular region, where it exited the monkey. The catheter was enclosed in the tether until it exited the back of the cage, where it was joined to additional silicone tubing. The silicone tubing was attached to a filter (Gilman Scientific, Ann Arbor, MI) and connected to an infusion pump (model MHRK55, Watson-Marlow Co., Falmouth, UK). This apparatus allowed the experimenter to draw blood from and infuse drugs to a monkey that was awake and able to move with minimal restraint. The apparatus and surgery procedures are described in detail elsewhere (e.g., Winger et al., 1975).

\section{Procedure}

Noncontingent Ethanol Administration. The four monkeys, two males and two females, participating in this experiment had histories of oral ethanol self-administration. Ethanol self-administration had ceased approximately 1.5 years before this experiment. The monkeys also participated in experiments examining the HPA response to intramuscular injections of opioid antagonists (Williams et al., 2003). Approximately 6 weeks separated the antagonist injections of that study and the manipulations of this experiment. They were randomized to receive either saline or ethanol at doses of $0.3,1$, and $1.8 \mathrm{~g} / \mathrm{kg}$. Each dose was given twice, with 1 week between doses. Ethanol was infused at concentrations of $4 \%(0.3$ $\mathrm{g} / \mathrm{kg}), 13 \%(1 \mathrm{~g} / \mathrm{kg})$, and $25 \%(1.8 \mathrm{~g} / \mathrm{kg})$. These ethanol concentrations were chosen so that the fluid volume infused would be constant across the different doses. The volume varied for each animal on the basis of the volume required to deliver the highest ethanol dose. Although the pumps were set to infuse fluid at $12 \mathrm{ml} / \mathrm{min}$, an infusion rate of $6 \mathrm{ml} / \mathrm{min}$ was achieved by turning the pump on for $30 \mathrm{sec}$ and off for $30 \mathrm{sec}$.

Initial blood samples were drawn at 9:30 AM ( $-30 \mathrm{~min}$ in the figures) and again at 9:45 AM. Ethanol infusions began at 9:55 AM ( $-5 \mathrm{~min})$ and lasted for 8 to $9 \mathrm{~min}$ for the smallest monkey and 17 to $18 \mathrm{~min}$ for the largest monkey. Blood sampling continued every $15 \mathrm{~min}$ for $1 \mathrm{hr}$ after the ethanol infusion and every $30 \mathrm{~min}$ for the next $2 \mathrm{hr}$.

After completing the previous manipulations, the monkeys received intramuscular injections of $0.32 \mathrm{mg} / \mathrm{kg}$ naltrexone just before the second blood sample ( $-15 \mathrm{~min})$, after which either saline or $1.8 \mathrm{~g} / \mathrm{kg}$ ethanol was infused. The monkeys experienced each condition twice, with 1 wk between conditions. Condition order was arranged so that one male and one female were exposed to naltrexone/saline and then naltrexone/ethanol; the order was reversed for the remaining monkeys.

Approximately $2 \mathrm{ml}$ of blood was drawn at 10 time points over the course of the day. Two blood samples were taken before the saline or ethanol infusion ( $-30 \mathrm{~min}$ and $-15 \mathrm{~min}$ ). After the infusion, samples were taken every $15 \mathrm{~min}$ for the first hour $(15,30,45$, and $60 \mathrm{~min})$ and then every $30 \mathrm{~min}$ until $185 \mathrm{~min}$ after the initiation of the ethanol infusion.

Response-Contingent Ethanol Administration. The five monkeys, four males and one female, used in this experiment were different from those subjects used for noncontingent ethanol administration. Their cages were equipped with a lever panel on the right side of the cage that had two response levers located beneath three stimulus lights. The red light on the right signaled drug availability. The green center light was illuminated for the duration of the drug infusion. The third light was not used.

The experiments were controlled by Med Associates software (St. Albans, VT) that was installed on computers in an adjacent room. Selfadministration periods occurred twice daily; one began at 10:00 AM, and the second began at 4:00 PM. Each period consisted of four 25-min response components, with each component separated by a 10-min timeout component (total session time, $130 \mathrm{~min}$ ). Blood samples were taken during the time-out components. During the response component, drug injections were delivered on a fixed-ratio 30 schedule of reinforcement. Because ethanol was delivered at $30 \% \mathrm{w} / \mathrm{v}$, large subjects required large fluid volumes and pump durations up to approximately $50 \mathrm{sec}$. Each injection was followed by a 60 -sec time out. Responding during the time between components and the postinjection time out had no consequences.

Self-administration training took place several months before this study. The monkeys were typically trained to lever-press for $0.1 \mathrm{mg} / \mathrm{kg}$ per injection of cocaine on a fixed-ratio 1 schedule. The response requirement was then increased to 20 or 30 , depending up the experiment. The monkeys self-administered a variety of psychoactive drugs while participating in different experiments. During the weeks before ethanol selfadministration, the monkeys had access to $0.1 \mathrm{mg} / \mathrm{kg}$ per injection of methohexital. Ethanol self-administration was established by using 0.03 $\mathrm{g} / \mathrm{kg}$ per injection of ethanol delivered with $30 \% \mathrm{w} / \mathrm{v}$ ethanol. Occasionally, saline was substituted for ethanol in the self-administration reservoir. 
The experimental conditions in this study included access to $0.03 \mathrm{~g} / \mathrm{kg}$ per injection of ethanol $30 \mathrm{~min}$ after receiving an intramuscular injection of saline or $0.01,0.03,0.1$, or $0.3 \mathrm{mg} / \mathrm{kg}$ naltrexone. Other conditions included access to intravenous saline $30 \mathrm{~min}$ after receiving an intramuscular injection of saline or $0.3 \mathrm{mg} / \mathrm{kg}$ naltrexone. The order was randomized for each monkey, with the exception that the last condition experienced for all monkeys was access to response-contingent saline infusions after receiving an injection of $0.3 \mathrm{mg} / \mathrm{kg}$ naltrexone. Blood samples were drawn once per week, and naltrexone was given no more than once per week. Naltrexone testing and blood sampling occurred during the morning self-administration period.

Approximately $2 \mathrm{ml}$ of blood was drawn before, during, and after the self-administration session for a total of 10 samples. Two blood samples were taken before the self-administration session $(-40$ and $-10 \mathrm{~min})$. Samples were taken during the session at the beginning of each time-out component $(25,60,95$, and $130 \mathrm{~min})$. Samples were also taken after the session at 165, 200, 260, and $320 \mathrm{~min}$.

Blood Collection and Handling. Each sample was placed in a 2-ml Vacutainer (Becton Dickinson, Franklin Lakes, NJ) containing $0.04 \mathrm{ml}$ of $7.5 \%$ ethylenediaminetetraacetic acid and immediately placed on ice. After each sample was drawn, the catheter was flushed with approximately $3 \mathrm{ml}$ of heparin saline (30 units/ml).

Blood samples were centrifuged at $4500 \mathrm{rpm}$ for $5 \mathrm{~min}$ at $4^{\circ} \mathrm{C}$. The plasma was pipetted into 2-ml Cryovials (Corning Costar Corp., Cambridge, MA) and stored at $-80^{\circ} \mathrm{C}$ until assayed for plasma ACTH and cortisol. The ACTH concentrations were measured by using commercially available radioimmunoassay kits (Nichols Institute Diagnostics, San Juan Capistrano, CA). The range of detection was 1 to $1500 \mathrm{pg} / \mathrm{ml}$. The intra-assay and interassay coefficients of variation were $3-3.2 \%$ and $6-8 \%$, respectively.

\section{Data Analysis}

The ACTH data are presented as time-course data (hormone concentrations at different time points throughout the session). The mean and SEM were calculated. These data were analyzed with a two-way repeatedmeasures ANOVA by using condition $\times$ time. For the data collected during noncontingent ethanol administration, the initial analysis compared the effects of saline and the three ethanol doses. This analysis was made to determine whether ethanol alone increased ACTH levels. The second analysis included the data collected when naltrexone was given in addition to ethanol.

For the data collected during response-contingent ethanol administration, the initial analysis compared the effects of $0.03 \mathrm{~g} / \mathrm{kg}$ per injection of ethanol in the presence of intramuscular injections of saline and the four naltrexone doses to determine whether naltrexone would alter the effects of ethanol on ACTH levels. The second analysis included the effects of intramuscular injections of saline and $0.3 \mathrm{mg} / \mathrm{kg}$ naltrexone when saline was available for self-administration. When significant effects $(p<0.05)$ were found, a post hoc Tukey's honestly significant difference test was applied.

Least-squares linear regression analysis was performed on the ethanol intake and the corresponding ACTH area under the curve (AUC) for ethanol self-administration. The AUCs were calculated by using the trapezoidal rule (Tallarida and Murray, 1987). The first sample collected (at $-30 \mathrm{~min}$ for noncontingent ethanol and $-40 \mathrm{~min}$ for response-contingent ethanol) was used as the reference for the calculation of the AUC for ACTH. The AUC was calculated for each subject and averaged across all subjects for conditions in which ethanol was self-administered.

The number of injections and the ethanol intake were each analyzed by using a one-way repeated-measures ANOVA followed by a post hoc Tukey's honestly significant difference test. Included in the analysis for the number of injections were the data for ethanol self-administration after intramuscular injections of saline and 0.01 to $0.3 \mathrm{mg} / \mathrm{kg}$ naltrexone.

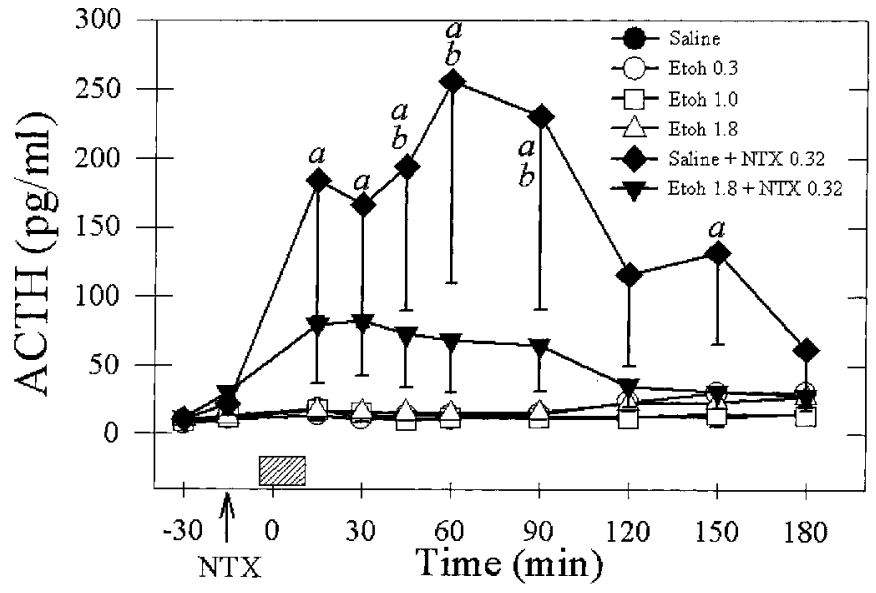

Fig. 1. ACTH levels $(\mathrm{pg} / \mathrm{ml})$ are plotted across time for four monkeys receiving noncontingent infusions of saline or $0.3,1.0$, and $1.8 \mathrm{~g} / \mathrm{kg}$ ethanol. Also shown is the effect of treatment with intramuscular injection of $0.32 \mathrm{mg} / \mathrm{kg}$ naltrexone before infusion with saline or $1.8 \mathrm{~g} / \mathrm{kg}$ ethanol. The lined bar along the $x$ axis indicates the approximate infusion duration. All infusions began at $-5 \mathrm{~min}$. The arrow at $-15 \mathrm{~min}$ indicates the time of naltrexone injection. ${ }^{a}$ Significant difference from saline infusion alone and all doses of ethanol alone at the same time points $(p<0.05)$; ${ }^{b}$ significant difference from $1.8 \mathrm{~g} / \mathrm{kg}$ ethanol with $0.32 \mathrm{mg} / \mathrm{kg}$ naltrexone at the same time points $(p<0.05)$. Etoh, ethanol; NTX, naltrexone.

\section{Drugs}

Ethanol 95\% (Pharmco Products Inc., Brookfield, CT) was mixed with $0.9 \%$ saline. Naltrexone hydrochloride (provided by the NIDA Research Technology Branch) was dissolved in sterile water.

\section{RESULTS}

Noncontingent intravenous administration of three doses of ethanol resulted in a small, but statistically significant, increase in plasma ACTH levels (Fig. 1, open symbols); there was a main effect of ethanol $[F(3,9)=4.32 ; p<0.05]$. This effect was not related to the dose of ethanol. Average ACTH levels after saline were 9 to $18 \mathrm{pg} / \mathrm{ml}$; after $0.3,1$, and $1.8 \mathrm{~g} / \mathrm{kg}$ ethanol, ACTH levels peaked at an average of 31,18 , and $27 \mathrm{pg} / \mathrm{ml}$, respectively. The effect was somewhat delayed as well, peaking $2 \mathrm{hr}$ after the intravenous infusion. After the largest dose of ethanol $(1.8 \mathrm{~g} / \mathrm{kg})$, the monkeys showed signs of intoxication such as reduced locomotor activity and ataxia.

Intramuscular injections of $0.32 \mathrm{mg} / \mathrm{kg}$ naltrexone produced variable but substantially greater increases in ACTH levels than did ethanol (Fig. 1, filled diamonds); there was a main effect of naltrexone $[F(5,15)=3.71 ; p<0.05]$. Average ACTH plasma levels were increased $30 \mathrm{~min}$ after naltrexone administration and peaked 75 min after naltrexone administration which are depicted as time 15 and time 60, respectively, in Fig. 1. The ACTH levels were quite variable across the subjects. For example, 60 min after naltrexone administration, ACTH levels ranged from 10 to $545 \mathrm{pg} / \mathrm{ml}$.

When intramuscular naltrexone $(0.32 \mathrm{mg} / \mathrm{kg})$ was administered before an intravenous bolus infusion of $1.8 \mathrm{~g} / \mathrm{kg}$ ethanol, ACTH levels over time were less than those produced by naltrexone alone. This difference was significant at the 45- to 90-min measurements. This combination of 


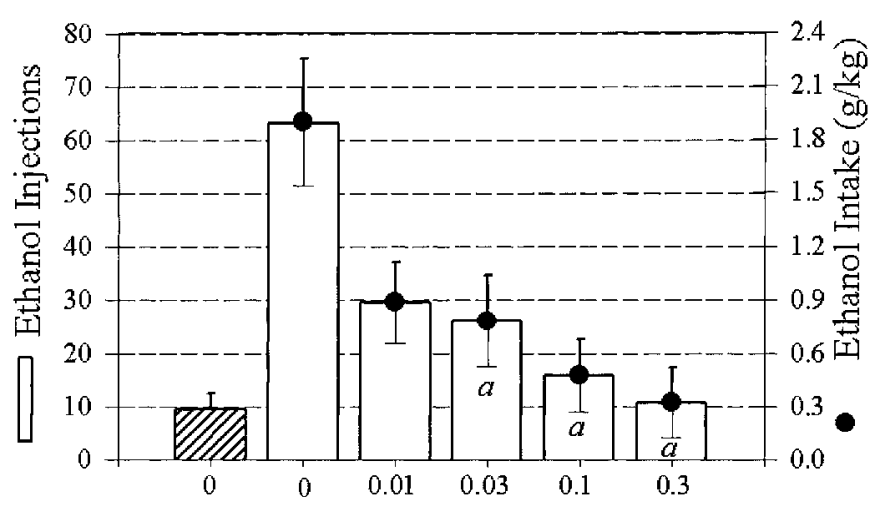

Pretreatment Condition (mg/kg NTX)

Fig. 2. The number of ethanol injections (open bars) and ethanol intake $(\mathrm{g} / \mathrm{kg}$; -) are shown for five monkeys receiving response-contingent ethanol $(0.03 \mathrm{~g} / \mathrm{kg}$ per injection) after pretreatment with intramuscular injections of saline or 0.01 to $0.3 \mathrm{mg} / \mathrm{kg}$ naltrexone. Response-contingent saline injections are depicted by the lined bar. ${ }^{a}$ Significant difference for number of ethanol injections and ethanol intake compared with those obtained with saline pretreatment $(p<0.05)$. NTX, naltrexone.

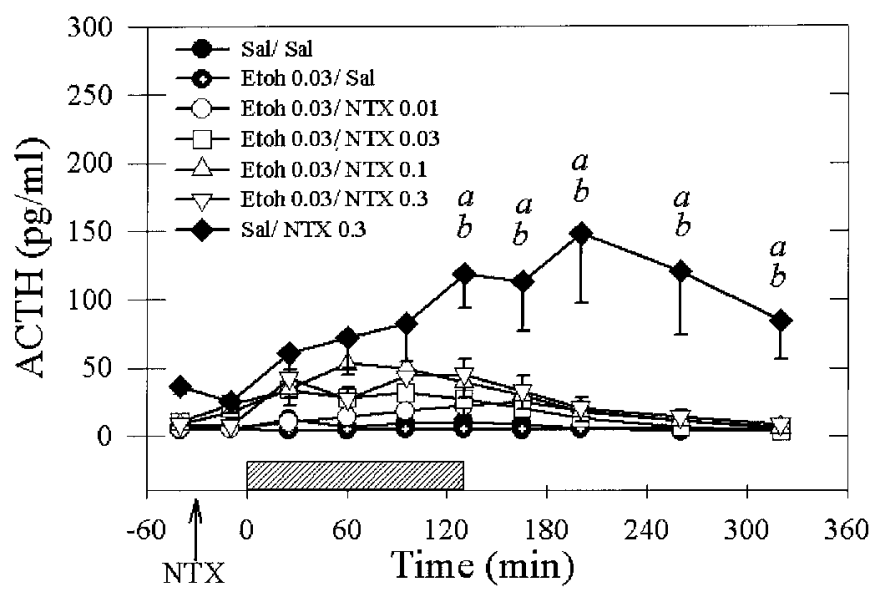

Fig. 3. ACTH levels $(\mathrm{pg} / \mathrm{ml})$ are plotted across time for five monkeys receiving response-contingent saline or ethanol $(0.03 \mathrm{~g} / \mathrm{kg}$ per injection) after pretreatment with intramuscular injections of saline or 0.01 to $0.3 \mathrm{mg} / \mathrm{kg}$ naltrexone. The lined bar along the $x$ axis indicates the duration of the self-administration session. The arrow at -15 min indicates the time of naltrexone injection. ${ }^{a} \mathrm{ACTH}$ levels were significantly different from those when ethanol was self-administered after intramuscular saline $(p<0.05) ;{ }^{b} \mathrm{ACTH}$ levels were significantly different from those when ethanol was self-administered after any dose of naltrexone $(p<0.05)$. Etoh, ethanol; NTX, naltrexone; Sal, saline.

naltrexone and $1.8 \mathrm{~g} / \mathrm{kg}$ ethanol produced larger ACTH levels than those produced by ethanol alone, and this difference was significant at all but the 120- and 180-min measurement times (Fig. 1).

When $0.03 \mathrm{~g} / \mathrm{kg}$ per injection of ethanol was made response contingent, monkeys took an average of 62 injections $(1.9 \mathrm{~g} / \mathrm{kg})$ during the session (Fig. 2). The monkeys received significantly fewer injections $(n=9)$ when response-contingent saline was available $[F(6,24)=8.07 ; p$ $<0.001]$. The self-administered ethanol did not alter ACTH levels (Fig. 3; closed circle with inserted cross) during or after the session. The average cumulative ethanol intake at the end of each of the four response components was $0.88,1.52,1.81$, and $1.9 \mathrm{~g} / \mathrm{kg}$; the average ACTH levels were 4 to $14 \mathrm{pg} / \mathrm{ml}$ during these periods of ethanol selfadministration, which was not significantly different from the ACTH levels of 5 to $12 \mathrm{pg} / \mathrm{ml}$ that were measured during saline self-administration after a saline pretreatment (Fig. 3; closed circles).

Pretreatment with intramuscular naltrexone $0.3 \mathrm{mg} / \mathrm{kg}$ before the opportunity to self-administer saline increased plasma ACTH (Fig. 3; closed diamonds). ACTH levels increased gradually after the naltrexone administration compared with the rate of increase after a bolus injection of saline in the previous part of this study (refer to Fig. 1). The peak values (119-148 pg/ml) developed between 130 and 260 min after naltrexone injection and were also lower than those obtained previously.

Pretreatment with increasing doses of naltrexone resulted in a dose-dependent decrease in number of ethanol injections taken and ethanol intake (Fig. 2). The number of ethanol injections was significantly decreased after administration of 0.03 to $0.3 \mathrm{mg} / \mathrm{kg}$ naltrexone $[F(4,16)=5.81 ; p<0.005]$.

When ethanol self-administration followed naltrexone administration, ACTH levels were greater than those produced by ethanol self-administration alone [main effect of naltrexone: $F(4,16)=5.65 ; p<0.005]$. For example, ACTH levels after ethanol with the two highest naltrexone doses (Fig. 3; open triangles and inverted open triangles) at various points between time 25 and 130 were greater than the ACTH levels after ethanol with saline at the same time points. However, the ACTH levels after all the ethanol/ naltrexone combinations were not statistically different from one another. When the analysis included saline selfadministration after $0.3 \mathrm{mg} / \mathrm{kg}$ naltrexone (closed diamonds), the ACTH levels for this condition were significantly higher than for all other manipulations from time 130 to the end of the sampling period $[F(9,36)=7.76 ; p<$ $0.005]$. When examined in the context of the saline selfadministration after $0.3 \mathrm{mg} / \mathrm{kg}$ naltrexone, the ethanol/saline and ethanol/naltrexone combinations failed to produce statistically significant effects. Thus, ethanol seemed to dampen the ACTH-stimulating effect of $0.3 \mathrm{mg} / \mathrm{kg}$ naltrexone (Fig. 3; open inverted triangles).

Least-squares linear regression analysis was performed on the ethanol intake and the corresponding ACTH AUC when intramuscular saline or 0.01 to $0.3 \mathrm{mg} / \mathrm{kg}$ naltrexone was given before ethanol self-administration (Fig. 4). The slope of the regression line was significantly less than 0 $[F(1,23)=23.7 ; p<0.001]$, indicating that ethanol intake was negatively correlated with ACTH AUC. The resulting regression equation was $y=-0.003 x+1.51$, and approximately $51 \%$ of the variance in the data was accounted for by the regression equation $(R=0.71)$.

\section{DISCUSSION}

Intravenous ethanol administration, either noncontingent or response contingent, did not result in marked in- 


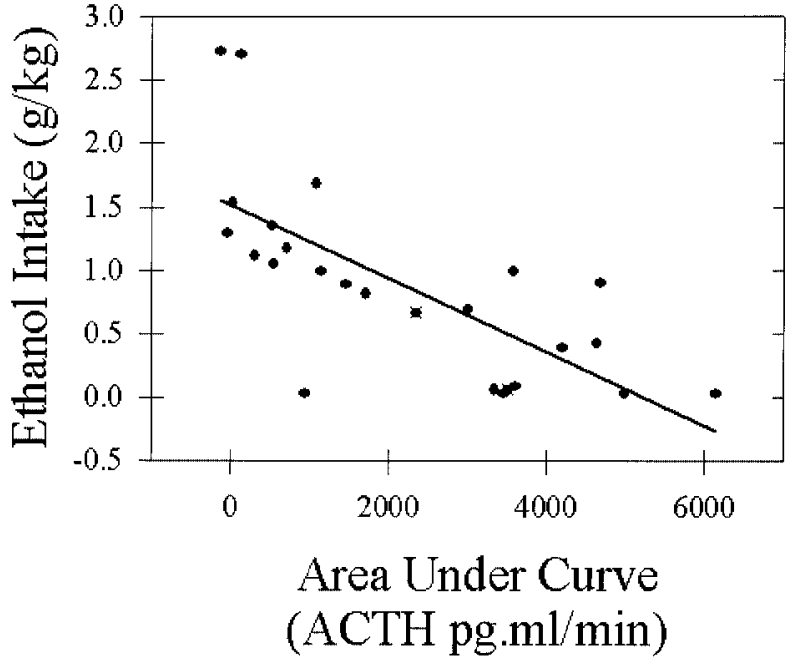

Fig. 4. Ethanol intake $(\mathrm{g} / \mathrm{kg})$ is plotted against the ACTH AUC $(\mathrm{pg} \cdot \mathrm{ml} / \mathrm{min})$. Least-squares linear regression analysis was performed on these data $\left(R^{2}=\right.$ 0.51). The regression line is also plotted.

creases in ACTH plasma levels. This result is in contrast to most studies in rats and humans, in which ethanol has been shown to stimulate the HPA axis (Inder et al., 1995; McCaul et al., 2001; Mendelson and Stein, 1966; Merry and Marks, 1969; Rivier, 1996). One factor that may play a role in ethanol's inability to increase ACTH levels in our experiments is the route of ethanol administration. Most reports of ethanol's HPA effects in humans involve oral consumption of ethanol. Oral ethanol has a number of foodlike qualities (e.g., gastric expansion, caloric value, and effects on insulin), and both ACTH and cortisol levels increase in humans after they have consumed a standardized meal (Al-Damluji et al., 1987; Dodt et al., 1994). Route of administration might also influence the ACTH increases that have been observed after intraperitoneal administration of ethanol to rats. Although various procedures have been used to reduce the irritation that results from ethanol in the peritoneum, it is possible that ethanol by the intraperitoneal route may be an irritant.

Evaluation of the HPA axis effects of intravenously delivered ethanol in rats and other animals, as well as humans, would help to clarify this issue. The few studies that have examined the effects of intravenous ethanol on HPA activity in humans (Davis and Jeffcoate, 1983; Jenkins and Connolly, 1968) found that cortisol increased only after ethanol doses that increased blood ethanol levels to greater than $100 \mathrm{mg} / 100 \mathrm{ml}$ and caused illness or dysphoria. Only one animal study was found that examined HPA activity after intravenous ethanol administration. Cudd et al. (1996) infused 0.5 to $2 \mathrm{~g} / \mathrm{kg}$ ethanol intravenously into sheep over $60 \mathrm{~min}$. Ethanol increased ACTH levels, but the effects were not dose related, and ACTH levels were as high after only a saline injection.

In contrast to the finding that intravenous ethanol did not increase ACTH levels, intramuscular naltrexone produced large increases of plasma ACTH. This result repli- cates those from a study in which we examined the ability of naltrexone and other opioid receptor-selective antagonists to increase plasma ACTH and cortisol levels (Williams et al., 2003). Although the magnitude of the HPA response to naltrexone is larger and more variable in this experiment, the effective doses and the HPA response pattern are similar to those from the previous study. This finding also agrees with the findings in humans that acute administration of various opioid antagonists increases HPA activity. For example, intravenous naloxone and nalmefene increase plasma ACTH and cortisol (Jackson et al., 1995; Schluger et al., 1998; Wand et al., 1999). Oral naltrexone increases plasma ACTH and cortisol (Farren et al., 1999; King et al., 2002). However, there are interactive effects of ethanol and naltrexone on the HPA axis. McCaul et al. (2001) demonstrated that naltrexone blocked ethanol-induced activation of the HPA axis even though naltrexone's direct effects on the HPA axis had long since disappeared (approximately 15 hr after naltrexone administration). O'Malley et al. (2002) showed that naltrexone augmented ethanol's effect on the HPA axis despite blood sampling $6 \mathrm{hr}$ after naltrexone, a time when naltrexone's direct effects on the HPA axis are declining (Farren et al., 1999; King et al., 2002). These human studies suggest that we may also observe an interaction between naltrexone and ethanol on ACTH levels. In the current experiments, noncontingently delivered ethanol attenuated naltrexone-induced increases in plasma ACTH. Ethanol has been shown to impair HPA sensitivity to other stimuli. For example, ethanol blocked the ACTH increase stimulated by ovine corticotropin-releasing hormone (Waltman et al., 1994). It is not clear how these different HPA effects of naltrexone are related to the therapeutic reduction of alcohol consumption observed clinically.

The magnitude and timing of naltrexone's effect on ACTH levels were different depending on the context in which the infusions were given (i.e., noncontingent or response-contingent ethanol/saline infusions). When naltrexone was given before a noncontingent infusion of saline, ACTH levels increased within $30 \mathrm{~min}$ of the naltrexone injection. Peak ACTH levels of $255 \mathrm{pg} / \mathrm{ml}$ were reached 75 to $105 \mathrm{~min}$ after the injection, and these values had decreased to prenaltrexone levels by $195 \mathrm{~min}$ after the injection. This pattern of ACTH response to naltrexone was similar to that found in a previous study in this laboratory that used similar conditions (Williams et al., 2003). When naltrexone was given before a session in which response-contingent saline was available, peak ACTH increases occurred more than $3 \mathrm{hr}$ after the naltrexone injection, and the ACTH levels were still increased $5.5 \mathrm{hr}$ after the administration of naltrexone. The delayed and attenuated ACTH response to naltrexone when responsecontingent saline was available might be due to learning processes associated with the self-administration experience. All monkeys experienced naltrexone with responsecontingent saline after they had an extensive history of ethanol self-administration in the presence of naltrexone. It 
is possible that the experience of the attenuating effect of ethanol on the ACTH-enhancing effect of naltrexone became conditioned under these repeated exposures and that it is this conditioned suppression that reduced the ability of naltrexone to stimulate ACTH release when it was given before saline self-administration.

It is interesting to note that the ACTH increases after 0.3 $\mathrm{mg} / \mathrm{kg}$ naltrexone were quite modest when ethanol was available after the injection, even though this dose of naltrexone reduced the amount of ethanol taken only to 0.32 $\mathrm{g} / \mathrm{kg}$ on average. A part of this ethanol-induced attenuation of naltrexone's effects on ACTH levels may also have been a conditioned effect.

This study indicates that the interaction of naltrexone and ethanol on the HPA axis does not depend on whether ethanol was self-administered or delivered by the experimenter; noncontingent ethanol was able to reduce naltrexone-induced increases in plasma ACTH. Because intravenous ethanol in the monkey did not increase these hormones as oral ethanol does in humans, this study does not effectively answer the question of whether naltrexone dampens (McCaul et al., 2001) or enhances (O'Malley et al., 2002) the HPA-stimulating effects of ethanol. However, there was a strong negative correlation between ethanol intake and ACTH plasma levels over time in the monkey, similar to the negative correlation that was observed between cortisol levels and intensity of alcohol craving and drinks taken by humans (O'Malley et al., 2002). In both this study and that of O'Malley et al., high stress hormone levels after ethanol consumption in the presence of naltrexone may be related to the ability of naltrexone to suppress ethanol drinking. Noncontingent ethanol administration clearly suppressed naltrexone's effect on ACTH levels, and this same relationship may be applied to responsecontingent ethanol administration. Because naltrexone reduced ethanol self-administration, there was less ethanol present to exert an inhibitory influence on naltrexone's ability to increase HPA activity.

\section{ACKNOWLEDGMENTS}

We thank Gail Winger for help with manuscript preparation and Nick Jones and Partha Mukhopadhyay for technical assistance.

\section{REFERENCES}

Al-Damluji S, Iveson T, Thomas JM, Pendlebury DJ, Rees LH, Besser GM (1987) Food-induced cortisol secretion is mediated by central alpha-1 adrenoreceptor modulation of pituitary ACTH secretion. Clin Endocrinol 26:629-636.

Cudd TA, Chen WJ, West JR (1996) Acute hemodynamic, pituitary, and adrenocortical responses to alcohol in adult female sheep. Alcohol Clin Exp Res 20:1675-1681.

Davis JRE, Jeffcoate WJ (1983) Lack of effect of ethanol on plasma cortisol in man. Clin Endocrinol 19:461-466.
Dodt C, Hansen K, Uthgenannt D, Born J, Fehm HL (1994) Cholinergic potentiation of the meal-induced rise in ACTH and cortisol concentrations in men. Exp Clin Endocrinol 102:460-466.

Farren CK, O’Malley S, Grebski G, Maniar S, Porter M, Kreek MJ (1999) Variable dose naltrexone-induced hypothalamic-pituitary-adrenal stimulation in abstinent alcoholics: a preliminary study. Alcohol Clin Exp Res 23:502-508.

Inder WJ, Joyce PR, Wells JE, Evans MJ, Ellis MJ, Mattioll L, Donald RA (1995) The acute effects of oral ethanol on the hypothalamic-pituitaryadrenal axis in normal human subjects. Clin Endocrinol 42:65-71.

Jackson RV, Grice JE, Hockings GI, Torpy DJ (1995) Naloxone-induced ACTH release: mechanism of action in humans. Clin Endocrinol 43: 423-424.

Jenkins JS, Connolly J (1968) Adrenocortical response to ethanol in man. Br Med J 2:804-805.

King AC, Schluger J, Gunduz M, Borg L, Perret G, Ho A, Kreek MJ (2002) Hypothalamic-pituitary-adrenocortical (HPA) axis response and biotransformation of oral naltrexone: preliminary examination of relationship to family history of alcoholism. Neuropsychopharmacology 26:778-788.

McCaul ME, Wand GS, Stauffer R, Lee SM, Rohde CA (2001) Naltrexone dampens ethanol-induced cardiovascular and hypothalamicpituitary-adrenal axis activation. Neuropsychopharmacology 25:537-547.

Mendelson JH, Mello NK, Cristofaro P, Skupny A, Ellingboe J (1986) Use of naltrexone as a provocative test for hypothalamic-pituitary hormone function. Pharmacol Biochem Behav 24:309-313.

Mendelson JH, Stein S (1966) Serum cortisol levels in alcoholic and nonalcoholic subjects during experimentally induced ethanol intoxication. Psychosom Med 28:616-626.

Merry J, Marks V (1969) Plasma-hydrocortisone response to ethanol in chronic alcoholics. Lancet 2:107-108.

National Research Council (1996) Guide for the Care and Use of Laboratory Animals. National Academy Press, Washington, DC.

O’Malley SS, Krishnan-Sarin S, Farren C, Sinha R, Kreek J (2002) Naltrexone decreases craving and alcohol self-administration in alcoholdependent subjects and activates the hypothalamo-pituitaryadrenocortical axis. Psychopharmacology (Berl) 160:19-29.

Rivier C (1996) Alcohol stimulates ACTH secretion in the rat: mechanisms of action and interactions with other stimuli. Alcohol Clin Exp Res 20:240-254.

Schluger JH, Ho A, Borg L, Porter M, Maniar S, Gunduz M, Perret G, King A, Kreek MJ (1998) Nalmefene causes greater hypothalamic pituitary-adrenal axis activation than naloxone in normal volunteers: implications for the treatment of alcoholism. Alcohol Clin Exp Res 22:1430-1436.

Tallarida RJ, Murray RB (1987) Manual of Pharmacologic Calculations With Computer Programs. Springer, New York.

Waltman C, McCaul ME, Wand GS (1994) Adrenocorticotropin responses following administration of ethanol and ovine corticotropinreleasing hormone in the sons of alcoholics and control subjects. Alcohol Clin Exp Res 18:826-830.

Wand G, McCaul ME, Gotjen D, Reynolds J, Lee S (2001) Confirmation that offspring from families with alcohol-dependent individuals have greater hypothalamic-pituitary-adrenal axis activation induced by naloxone compared with offspring without a family history of alcohol dependence. Alcohol Clin Exp Res 25:1134-1139.

Wand GS, Mangold D, Ali M (1999) Adrenocorticotropin responses to naloxone in sons of alcohol-dependent men. J Clin Endocrinol Metab 84:64-68.

Williams KL, Holden Ko MC, Rice KC, Woods JH (2003) Effect of opioid receptor antagonists on hypothalamic-pituitary-adrenal activity in rhesus monkeys. Psychoneuroendocrinology 28:513-528.

Winger G, Stitzer ML, Woods JH (1975) Barbiturate-reinforced responding in rhesus monkeys: comparisons of drugs with different durations of action. J Pharmacol Exp Ther 195:505-514. 